\title{
Effectiveness of bundled interventions in reducing surgical site infections in elective caesarean sections and caesarean hysterectomies in a tertiary care centre
}

\author{
Gunjan Yadav ${ }^{1 *}$, Kalpana Yadav', Parasuram Waddar ${ }^{2}$
}

${ }^{1}$ Department of Obstetrics and Gynecology, Shyam Shah Medical College, Rewa, Madhya Pradesh, India

${ }^{2}$ Department of Pediatrics, Shyam Shah Medical College, Rewa, Madhya Pradesh, India

Received: 18 April 2020

Accepted: 28 May 2020

\author{
*Correspondence: \\ Dr. Gunjan Yadav, \\ E-mail: dr.gunjan.2019@gmail.com
}

Copyright: ( ) the author(s), publisher and licensee Medip Academy. This is an open-access article distributed under the terms of the Creative Commons Attribution Non-Commercial License, which permits unrestricted non-commercial use, distribution, and reproduction in any medium, provided the original work is properly cited.

\begin{abstract}
Background: Surgical site infections are the most common and easily preventable infections complicating surgeries. CDC recommends certain bundle interventions for the prevention of SSIs. Hence the present study was undertaken to see the effectiveness and feasibility of the bundle interventions in the elective caesarean sections and caesarean hysterectomies.

Methods: A total of 600 patients were taken. Bundled interventions were applied in 278 caesarean sections and 26 caesarean hysterectomies. Routine care was implemented in 262 caesarean sections and 34 caesarean hysterectomies. Rate of SSI, risk factors associated and treatment outcomes were studied.

Results: 8 out of 304 cases of the bundled intervention group developed SSI, giving a rate of $2.6 \%$. 52 cases out of 296 in the routine care group developed SSI, the SSI rate being 17.5\%. Anemia and diabetes were the most common risk factors.

Conclusions: Adherence to bundled interventions can significantly and easily reduce the incidence of SSI.
\end{abstract}

Keywords: Bundled intervention, Caesarean hysterectomy, Caesarean sections, Surgical site infections

\section{INTRODUCTION}

Surgical site infections (SSIs) are infections of the incision or organ or space that occur after surgery within 30 days of surgery1. Surgical site infections (SSIs) can lead to substantial morbidity, prolonged hospitalization, increased costs, and death in patients. The incidence of SSI is 6 to $11 \%$ in patients undergoing inpatient surgery. SSI ranks as the most-costly of all hospital acquired infections. The most widely used definition of SSI has been provided by the CDC. According to this definition, SSIs are classified by depth and tissue spaces involved. A superficial incisional SSI involves only the skin or subcutaneous tissue. A deep incisional SSI involves the fascia or muscle layers, and an organ space SSI involves any part of the body opened or manipulated during a procedure, excluding the previously mentioned layers.
Duration of SSI is an important risk factor for SSI according to the American Society of Anaesthesiologists (ASA). ${ }^{2}$ SSI are both common and morbid. SSI are now the most common and costly of all hospital acquired infections, accounting for $20 \%$ of all hospital acquired infections. SSI are associated with increased length of stay and a 2 to 11 -fold increase in the risk of mortality. Although most patients recover from an SSI without long term adverse sequelae, $77 \%$ of mortality in patients with an SSI can be attributed to the infection itself. ${ }^{3-6}$

'Bundled intervention' are the guidelines provided by the CDC for prevention of surgical site infection. Caesarean sections are very commonly performed surgeries in every hospital. Caesarean hysterectomies are also not uncommon. There is also an increasing trend in the number of caesarean sections in the past few years. As 
per the latest data (National Family Health Survey 201516 (NFHS-4), the caesarean rates at population level in India seem to be $17.2 \% .^{7}$ Therefore the risk of SSI is also increasing. The present study was therefore conducted to evaluate the feasibility and effectiveness of the bundled intervention in decreasing the SSI in caesarean sections and caesarean hysterectomies performed in study hospital.

To study the effect of bundled intervention in reducing surgical site infections in caesarean sections and caesarean hysterectomies.

\section{METHODS}

This prospective interventional study was conducted in department of obstetrics and gynecology in S. S. Medical College, Rewa from February 2019 to January 2020 over a period of 12 months. 600 women were selected based on the following inclusion and exclusion criteria.

\section{Inclusion criteria}

- Women undergoing elective caesarean section for various indications like cephalopelvic disproportion, gestational diabetes mellitus, malpresentation

- Women undergoing elective caesarean hysterectomy for various indications like preop diagnosed morbidly adherent placenta, fibroid uterus.

\section{Exclusion criteria}

- Women undergoing emergency caesarean sections or caesarean hysterectomy

- Women not giving consent for the study.

All study subjects were analysed thoroughly regarding age, parity, previous obstetric history. A thorough general, physical, systemic and obstetric examination was done. A detailed history was taken regarding medical and surgical history and co-morbidities like diabetes mellitus and hypertension. A detailed drug history was also taken. Bundled interventions were divided into pre-operative, intra operative and post-operative care and implemented as follows:

\section{Pre-operative}

- Antibacterial soap bath the night before and morning of surgery

- Single shot of antibiotic ceftriaxone+ sulbactam 1.5 gm i.v. 30 minutes before surgery

- No hair removal.

\section{Intra-operative}

- Cleaning of abdomen by savlon and spirit followed by painting by povidone iodine
- Gloves were changed by surgeons and nurses after closure of peritoneum

- Rectus sheath was closed in single layer by vicryl no. 1-0

- Subcutaneous tissue was closed with interrupted sutures with chromic no. 1-0 if depth of subcutaneous tissue was $>2.5 \mathrm{~cm}$

- Skin was closed with nylon 1-0 with mattress sutures

- Duration of surgery was noted.

\section{Post-operative}

- Inj. ceftriaxone+ sulbactam 1.5 gm i.v. 12 hourly for 48 hours

- $\quad$ Dressing on post op day 3

- Suture removal on day 7 for pfannensteil incision and day 10 for vertical incision.

In the routine care group, preoperatively antiseptic soap bathing and antibiotic administration was not done. Hair were not removed. Intraoperatively gloves were not changed after closure of peritoneum. Post-operatively Inj amikacin $500 \mathrm{mg}$ i.v. 12 hourly for 48 hours was also administered.

Signs and symptoms of SSI, like redness, tenderness, fever, induration and pus discharge were noted. Pus culture was sent for culture sensitivity and the microbes were noted. Rate of SSI in relation to the type of surgery and comorbidities present were noted. Treatment required for SSI was also noted.

\section{Statistical analysis}

The data was analysed using various statistical analyses like SPSS. Various tests for calculation of standard deviation were applied and $\mathrm{p}$ value was calculated.

\section{RESULTS}

In the present study, total 540 caesarean sections and 60 elective caesarean hysterectomies were included based on the inclusion and exclusion criteria. Out of these, 278 caesarean sections and 26 elective caesarean hysterectomies were included in the bundled intervention group while 262 caesarean sections and 34 elective caesarean hysterectomies were included in the routine care group. In the present study, $1.9 \%$ cases in the intervention group developed superficial SSI while $10.8 \%$ cases in the routine group developed superficial SSI which is significantly high $(\mathrm{p}<0.001)$. Only $0.2 \%$ cases in the intervention group developed deep SSI which is significantly lower than $6.7 \%$ cases in the routine group that developed deep SSI $(\mathrm{p}<0.001)$.

In the present study, $1.08 \%$ of caesarean sections developed SSI in the intervention group which is significantly less than the $16.4 \%$ caesarean sections that developed SSI in the routine care group $(\mathrm{p}<0.001) .19 .4 \%$ 
cases undergoing caesarean hysterectomy developed SSI in the intervention group which is proportionately lower than $26.4 \%$ of the caesarean hysterectomies that developed SSI in the routine care group. However, it was not statistically significant.

In the present study, anemia and diabetes mellitus were the most common comorbidities seen in both the groups. $121 / 304(39.8 \%)$ cases had comorbidities in the intervention group while 127/296 (42.9\%) cases had comorbidities in the routine care group which is not significantly different than the intervention group. However, only 5.7 and cases in the intervention group developed SSI which is significantly lower than the $32.3 \%$ cases that developed SSI in the routine care group $(\mathrm{p}<0.001)$.

Table 1: Division of cases.

\begin{tabular}{|llll|}
\hline $\begin{array}{l}\text { Division of } \\
\text { cases }\end{array}$ & $\begin{array}{l}\text { Intervention } \\
\text { group }\end{array}$ & $\begin{array}{l}\text { Routine } \\
\text { care group }\end{array}$ & Total \\
\hline $\begin{array}{l}\text { Caesarean } \\
\text { sections }\end{array}$ & 278 & 262 & 540 \\
\hline $\begin{array}{l}\text { Elective caesarean } \\
\text { hysterectomies }\end{array}$ & 26 & 34 & 60 \\
\hline
\end{tabular}

Table 2: Rate and type of SSI in different groups.

\begin{tabular}{|lllllllll|}
\hline Type of SSI & Intervention group & \multicolumn{2}{c|}{ Routine group } & \multicolumn{3}{c|}{ Total SSI } & p value \\
\hline & No. of SSI & Total cases & \% & No. of SSI & Total cases & \% & & \\
\hline Superficial SSI & 6 & 304 & $1.9 \%$ & 32 & 296 & $10.8 \%$ & 38 & $<0.001$ \\
\hline Deep SSI & 2 & 304 & $0.6 \%$ & 20 & 296 & $6.7 \%$ & 22 & $<0.001$ \\
\hline Organ space SSI & 0 & 304 & $0 \%$ & 0 & 296 & $0 \%$ & 0 & 0 \\
\hline
\end{tabular}

Table 3: Rate of SSI in different surgeries.

\begin{tabular}{|c|c|c|c|c|c|c|c|c|}
\hline Type of surgery & Interventio & group & & Routine gr & & & Total & p value \\
\hline & No. of SSI & Total cases & $\%$ & No. of SSI & Total cases & $\%$ & & \\
\hline $\begin{array}{l}\text { Caesarean } \\
\text { sections }\end{array}$ & 3 & 278 & $1.08 \%$ & 43 & 262 & $16.4 \%$ & 46 & $<0.001$ \\
\hline $\begin{array}{l}\text { Elective caesarean } \\
\text { hysterectomies }\end{array}$ & 5 & 26 & $19.2 \%$ & 9 & 34 & $26.4 \%$ & 14 & $>0.001$ \\
\hline
\end{tabular}

Table 4: Relation of comorbidities and rate of SSI.

\begin{tabular}{|c|c|c|c|c|c|c|c|c|}
\hline \multirow[t]{2}{*}{ Co morbidity } & \multicolumn{3}{|c|}{ Intervention group } & \multicolumn{3}{|l|}{ Routine group } & \multirow[t]{2}{*}{ Total } & \multirow[t]{2}{*}{ p value } \\
\hline & $\begin{array}{l}\text { No. of cases } \\
\text { with/without } \\
\text { co morbidity }\end{array}$ & $\begin{array}{l}\text { No. of cases } \\
\text { developing } \\
\text { SSI }\end{array}$ & $\%$ & $\begin{array}{l}\text { No. of cases } \\
\text { with/without } \\
\text { co morbidity }\end{array}$ & $\begin{array}{l}\text { No. of cases } \\
\text { developing } \\
\text { SSI }\end{array}$ & $\%$ & & \\
\hline $\begin{array}{l}\text { Anaemia/ } \\
\text { diabetes/ any other }\end{array}$ & 121 & 7 & $5.7 \%$ & 127 & 41 & $32.3 \%$ & 48 & $<0.001$ \\
\hline None & 183 & 1 & $0.5 \%$ & 169 & 11 & $6.5 \%$ & 12 & $<0.001$ \\
\hline
\end{tabular}

Table 5: Methods of treatment of SSI.

\begin{tabular}{|c|c|c|c|c|c|c|}
\hline \multirow{2}{*}{ Treatment } & \multicolumn{2}{|c|}{ Intervention group } & \multicolumn{2}{|c|}{ Routine group } & \multirow[t]{2}{*}{ Total } & \multirow[t]{2}{*}{ p value } \\
\hline & No. & $\%$ & No. & $\%$ & & \\
\hline Antibiotics (oral/i.v.) & 8 & $100 \%$ & 52 & $100 \%$ & 60 & $>0.001$ \\
\hline Daily dressing & 4 & $50 \%$ & 41 & $79 \%$ & 46 & $>0.001$ \\
\hline Resuturing & 2 & $24 \%$ & 18 & $34 \%$ & 14 & $>0.001$ \\
\hline
\end{tabular}

Table 6: Rate of SSI in relation to duration of surgery.

\begin{tabular}{|c|c|c|c|c|c|c|c|c|}
\hline \multirow[t]{2}{*}{$\begin{array}{l}\text { Duration of } \\
\text { surgery }\end{array}$} & \multicolumn{3}{|c|}{ Intervention group } & \multicolumn{3}{|c|}{ Routine group } & \multirow[t]{2}{*}{ Total } & \multirow[t]{2}{*}{ p value } \\
\hline & No. of cases & No. of SSI & $\%$ & No. of cases & No. of SSI & $\%$ & & \\
\hline$<120 \mathrm{~min}$ & 96 & 0 & $0 \%$ & 109 & 3 & $2.7 \%$ & 3 & $>0.001$ \\
\hline$>120 \mathrm{~min}$ & 208 & 8 & $3.8 \%$ & 187 & 49 & $26 \%$ & 57 & $<0.001$ \\
\hline
\end{tabular}


In the intervention group, only $0.5 \%$ cases of the comorbidity free group developed SSI, while in the routine care group, $6.5 \%$ cases of the comorbidity free group developed SSI which is statistically significant $(\mathrm{p}<0.001)$.

In the present study, proportionately higher number of cases in the routine group required daily dressing administration and resuturing for the treatment of SSI as compared to intervention group. $100 \%$ of the cases in both the groups required antibiotic administration for 5-7 days post operatively. $24 \%$ cases in the intervention group required resuturing which is much less than the $34 \%$ cases that required resuturing in the routine group.

In the present study, statistically significant difference was not found in the development of SSI when the duration of surgery was less than 120 minutes. However, when the duration of surgery was more than 120 minutes, only $3.8 \%$ cases in the intervention group developed SSI which is significantly lower than the $26 \%$ cases that developed SSI in the routine care group $(\mathrm{p}<0.001)$.

\section{DISCUSSION}

Surgical site infection (SSI) is an important complication of obstetric surgeries and a key quality indicator of patient care. SSIs are potentially avoidable post-operative complications. Implementation of the described bundled intervention can significantly decrease the overall rate of SSI from $17.5 \%$ to $2.6 \%$.

In the present study, total 600 cases were selected, out of which 304 cases were included in the interventional group in which the bundled interventions were applied, and 296 cases were included in the routine care group. This can be seen in Table 1 .

Table 2 shows that out of 304 cases in the interventional group, only 8 cases i.e. $2.6 \%$ cases developed SSI which is significantly lower than the routine group in which 52 out of 296 total cases (17.5\%) developed SSI. Similar results were obtained by Lippit $\mathrm{MH}$ et al. ${ }^{8}$ In their study, 219 patients were selected who underwent ovarian surgeries, out of which, 91 patients were treated in the historical pre-bundle cohort and 128 treated in the postbundle implementation group. The overall surgical site infection rate in the pre-bundle cohort was $20 \%$ (18/91). After implementation of the 5-point surgical site infection prevention bundle, the infection rate decreased significantly to $3 \%$. This clearly shows that implementation of the simple bundle interventions proposed by CDC can significantly reduce the incidence of SSI. Similar results were obtained by Taylor JS et al, in the disinfect initiative, who found the rate of SSI $12.5 \%$ in pre bundle group and $7.4 \%$ in post bundle group. ${ }^{9}$

Table 3 shows the association of the rate of SSI with type of surgery. Caesarean sections are comparatively easier and less complicated than caesarean hysterectomy. There is increased tissue handling and tissue injury in caesarean hysterectomy. This leads to more chances of development of loci of infection in caesarean hysterectomy and thus development of SSI. Similar inference has been drawn out in this study in which there is higher incidence of SSI in the caesarean hysterectomy group as compared to the caesarean section group. This difference is statistically significant in the caesarean section group in which bundled interventions were applied compared to the routine care group. Lippitt $\mathrm{MH}$ et al, in their study on outcomes associated with a five-point SSI prevention bundle in women undergoing surgery for ovarian cancer found $20 \%$ rate of SSI in pre bundle group, ovarian cancer surgery being complex and time-consuming surgeries. $^{8}$

Table 4 shows the relation between presence of comorbidities and development of SSI. The presence of comorbidities hinders the process of healing of the tissues. Anemia and diabetes are the most common comorbidities found in this study in both the groups. The application of bundled interventions leads to a decrease in the development of SSI which is clearly seen in this study. In a study by Mahdi $\mathrm{H}$ et at, preoperative anemia was one of the major risk factors associated with development of SSI in women undergoing surgery for gynecologic cancer. ${ }^{10}$ Bakkum Gamez JN et al, in their study found significant association between hyperglycemia, anemia and smoking habits in the patient with increased risk of development of SSI. ${ }^{11}$

In Table 5, the treatment modes for SSI and their outcomes are compared in the 2 groups. I.V. antibiotics were required in $100 \%$ cases of both the groups. Interventional group received inj. ceftriaxone + sulbactam I.V. while routine care group received additional inj. amikacin I.V. Since the rate of SSI was less in interventional group, less antibiotics were required in that group compared to the routine group. This clearly indicated that application of bundled interventions can lead to a decrease in the financial burden of the hospital. Less number of patients required resuturing in the interventional group, thus decreasing the hospital stay and further reduction in the financial load of the hospital. O'Donnell RL et al, in their study found that $33 \%$ of women with SSI had prolonged hospital stay. ${ }^{12}$

Table 6 shows the relationship between duration of surgery and rate of development of SSI which is proportionate. As the time duration of surgery increases, there is more chance for the infectious organisms to settle in the operated area and proliferate. In a study by Schiavone MB et al of 233 identified patients, 115 had undergone colon surgery prior to (PRE) and 118 after (POST) the implementation of the intervention. ${ }^{13}$ In patients whose operation took longer than $360 \mathrm{~min}, 30$ day SSI rates were $37 \%$ (28/76) and $12 \%$ (8/67), respectively $(\mathrm{p} \leq 0.001)$. Tran $\mathrm{CW}$ et al, Nugent EK and Nguyen et al, in their study also found significant 
association between increase in the duration of surgery and development of SSI. ${ }^{14-16}$

\section{CONCLUSION}

Surgical site infection is a major contributing factor to perioperative morbidity and mortality and high costs of care in surgical patients. Surgical patients initially seen with more complex comorbidities and the emergence of antimicrobial-resistant pathogens increase the cost and challenge of treating SSIs. A large proportion of SSIs are preventable by application of evidence-based strategies. This study concludes that the implementation of SSI reduction bundle can significantly reduce 30-day SSIs in the patients. The interventions are effective in patients undergoing longer and more complex operations.

Funding: No funding sources

Conflict of interest: None declared

Ethical approval: The study was approved by the Institutional Ethics Committee

\section{REFERENCES}

1. National Healthcare Safety Network, Centers for Disease Control and Prevention. Surgical site infection (SSI) event. Available at: http://www.cdc.gov/nhsn/pdfs/pscmanual/9pscssicur rent.pdf. Accessed on $25^{\text {th }}$ January 2017.

2. Cheadle WG. Risk factors for surgical site infection. Surg Infect. 2006;7 (supplement 1):S7-S11.

3. Anderson DJ, Podgorny K, Berrios-Torres SI, Bratzler DW, Dellinger EP, Greene L, et al, Strategies to prevent surgical site infections in acute care hospitals: 2014 update. Infect Control Hosp Epidemiol. 2014;35:605-27.

4. Bratzler DW, Dellinger EP, Olsen KM, Perl TM, Auwaerter PG, Bolon MK, et al, Clinical practice guidelines for antimicrobial prophylaxis in surgery. Am J Health Syst Pharm. 2013;70:195-283.

5. Mangram AJ, Horan TC, Pearson ML, Silver LC, Jarvis WR. Guideline for prevention of surgical site infection, 1999. Infect Control Hosp Epidemiol. 1999;20:247-78.

6. Magill SS, Edwards JR, Bamberg W, Beldavs ZG, Dumyati G, Kainer MA, et al, Multistate pointprevalence survey of health care-associated infections. N Engl J Med. 2014;370:1198-208.

7. The federation of obstetric and gynaecological societies of India. Fogsi.org. 2019. Available at: https://www.fogsi.org/fogsi-cesarean-rates-jdt. Accessed on $20^{\text {th }}$ October 2019.
8. Lippitt MH, Fairbairn MG, Matsuno R, Stone RL, Tanner III EJ, Wick EC, et al. Outcomes associated with a five-point surgical site infection prevention bundle in women undergoing surgery for ovarian cancer. Obstet Gynecol. 2017;130(4):756-64.

9. Taylor JS, Marten CA, Munsell MF, Sun CC, Potts $\mathrm{KA}$, Burzawa JK, et al. The disinfect initiative: decreasing the incidence of surgical infections in gynecologic oncology. Ann Surg Oncol. 2017;24(2):362-8.

10. Mahdi H, Gojayev A, Buechel M, Knight J, SanMarco J, Lockhart D, et al. Surgical site infection in women undergoing surgery for gynecologic cancer. Int J Gynecol Cancer. 2014;24(4):779-86.

11. Bakkum-Gamez JN, Dowdy SC, Borah BJ, Haas LR, Mariani A, Martin JR, et al. Predictors and costs of surgical site infections in patients with endometrial cancer. Gynecol Oncol. 2013;130(1):100-6.

12. O’Donnell RL, Angelopoulos G, Beirne JP, Biliatis I, Bolton H, Bradbury M, et al. Impact of surgical site infection (SSI) following gynaecological cancer surgery in the UK: a trainee-led multicentre audit and service evaluation. BMJ Open. 2019;9(1):e024853.

13. Schiavone MB, Moukarzel L, Leong K, Zhou QC, Afonso AM, Iasonos A, et al. Surgical site infection reduction bundle in patients with gynecologic cancer undergoing colon surgery. Gynecol Oncol. 2017;147(1):115-9.

14. Tran CW, McGree ME, Weaver AL, Martin JR, Lemens MA, Cliby WA, et al. Surgical site infection after primary surgery for epithelial ovarian cancer: predictors and impact on survival. Gynecol Oncol. 2015;136(2):278-84.

15. Nugent EK, Hoff JT, Gao F, Massad LS, Case A, Zighelboim I, et al. Wound complications after gynecologic cancer surgery. Gynecol Oncol. 2011;121(2):347-52.

16. Van Nguyen JM, Sadeghi M, Gien LT, Covens A, Kupets R, Nathens AB, et al. Impact of a preventive bundle to reduce surgical site infections in gynecologic oncology. Gynecol Oncol. 2019;152(3):480-5.

Cite this article as: Yadav G, Yadav K, Waddar P. Effectiveness of bundled interventions in reducing surgical site infections in elective caesarean sections and caesarean hysterectomies in a tertiary care centre. Int J Reprod Contracept Obstet Gynecol 2020;9:2823-7. 